\title{
Awareness, Knowledge and Practice of Self-Medication among Undergraduates in Adeleke University, Ede, Osun State, Nigeria
}

\author{
Article by Temitope Feyisayo Asekun-Olarinmoye ${ }^{1}$, Aduragbemi Helen Akindiya ${ }^{2}$, \\ Oluyemi Julie Olowookere ${ }^{3}$, Ademola M. Omishakin ${ }^{4}$ \\ ${ }^{1,2,3,4}$ Department of Public Health, Faculty of Basic Medical Sciences, Adeleke \\ University, Ede, Osun State, Nigeria \\ E-mail: tasekunolarinmoye@gmail.com ${ }^{1}$, aduragbemiakindiya@yahoo.com ${ }^{2}$, \\ adeoyeoluyemi97@gmail.com ${ }^{3,}$ ife44@yahoo.com ${ }^{4}$
}

\begin{abstract}
Self-medication is the treatment of common health problems with medicines without medical supervision. There is substantive literature on self-medication, however there has been limited focus on undergraduates. Hence, this study aimed to bridge gaps in information on awareness, knowledge and practice of self-medication among respondents. Using cross-sectional study design and stratified random sampling technique, 418 consenting respondents were recruited into this study. Quantitative data was collected using a semi-structured, self-administered questionnaire; analyzed using SPSS version 21 and summarized using proportions and Chi-square tests $(p \leq 5 \%)$. Mean age of respondents was $19.89 \pm 2.83$ years, $52.4 \%$ were males while $47.6 \%$ were females. $97.8 \%$ had awareness about selfmedication, $66.0 \%$ had good knowledge on harmful effects of self-medication while $76.8 \%$ practiced self-medication. Analgesics was the most common drug used among respondents. Age and sex were statistically significantly associated with respondents' knowledge on harmful effects of self-medication $(p<0.05)$. Sex was statistically significantly associated with their practice of self-medication ( $p=0.006)$. There was a cognitive dissonance between respondents' knowledge and practice because though results showed that respondents had good knowledge, it did not translate into good practice. The university authorities need to develop intervention strategies to engender behavioral change which can potentially improve their practices towards self-medication.
\end{abstract}

Keywords: Awareness, Knowledge, Practice, Self-medication, Undergraduates.

\section{Introduction}

It is a natural phenomenon of life for people to feel unwell, hence, take action (health-seeking behaviors) towards regaining an equilibrium in health. On a daily basis, irrespective of how knowledgeable people may be, many acts on their health without prior consultation with qualified health personnel due to the desire for a relatively lower-costing solution. This is known as "self-care". Self-medication, as an element of self-care, is the selection and use of medicines by individuals to treat self-recognized illnesses or symptoms (World Health Organization, 2012). The World Self-Medication Industry (2010) further defines self-medication as, "the treatment of common health problems with medicines especially designed and labeled for use and approved as safe and effective for such use without medical supervision". Once a person obtains and consumes medicinal products in a bid to treat self- recognized disorders or symptoms without the advice of a physician, he/she can be termed as practicing self-medication (William, Phalke, Phalke, and Durgawale, 2006). It involves acquiring medicines without a prescription, resubmitting old prescriptions to purchase medicines, sharing medicines with relatives or members of one's circle or using leftover medicines stored at home (Loyola, Uchoa, Firmo and Lima-Costa, 2005).

Drugs frequently used without prescription include antimalarial, analgesics, antipyretics, antibiotics and cough syrups. The sources of these drugs people use without prescription, sometimes are from pharmacies or left-over drugs from previous medications (Musa, Awosan, Ibrahim, Abdullahi, Jafaar, Peter, Anthony and Isah, 2016). Individuals obtain information about drugs through print media, pharmacy, medicine dealers, family and friends. Hence, they feel equipped to handle health issues by themselves, especially when faced with limitations such as difficulties in accessing medical care. 
Increasing knowledge on how to deal with medications among populations, failures of health care systems in certain populations, availability of drugs in markets and poor drug regulatory practices are factors that contribute to self-medication. Other factors like demographic factors have been found to also influence self-medication. For instance, gender, age, sex and social role were discovered to have influence on self-medication (Girma, Diriba, Zerihun, Derbew, Abera, Mussie, Gebremedhin, Naod, Raghavendra and Abrham, 2011). It is a global public health issue of importance which is on a rapid rise/increase despite the dangers associated with it (Kumar, Kanchan, Unnikrishnan, Rekha, and Mithra, 2013; Osemene and Lamikanra, 2012). Many people trivialize ailments such as headache, fever, cough, throat infection, common cold and stomach ache while, some do perceive some ailments to be too mild to necessitate medical consultation.

A study carried out in Sokoto revealed that students indulged in self-medication to treat ailments such as fever, headache, body pain, cough/flu and diarrhea; the most frequently used drugs being pain killers, antimalarial, antibiotics, anti-flu and antidiarrheal (Musa et al., 2016). According to a study by Omolase, Adeleke and Afolabi (2012), the perceived simplicity of a health condition, financial constraints as well as non- availability of health care services were the main reasons for the practice of self-medication among respondents. People indulge in self-medication because while it helps them through their common health problems, it is time and cost saving especially for those who have few or no options as alternatives. The practice of self-medication must be based on authentic medical information otherwise irrational use of drugs can cause wastage of resources, increased resistance of pathogens, and can lead to serious health hazards. (Goldsworthy and Mayhorn, 2009). Though selfmedication is a popular preference worldwide, little is still known about its appropriateness, hence the need for a certain level of knowledge and health orientation in order to produce responsible selfmedication. In 2009, the World Self-Medication Industry reported that responsible self-medication can potentially reduce current burdens and challenges being faced by limited health care systems in various countries.

It is an acknowledged fact that the practice of self-medication (no matter the reason) is unacceptable (Sarahroodi, Arzi, Sawalha and Ashtarinezland, 2010). This requires giving heightened attention to the health-seeking behaviors people exhibit in our society in order to curb such unhealthy practices. There is a dearth of information on the awareness, knowledge and practices of self- medication among undergraduates in Adeleke University. It therefore became crucial to investigate these parameters to determine if they were aware of the dangers associated with self-medication and/or indulge in selfmedication and bridge gaps in information by providing valuable insight which the university community will utilize to prevent indulgence in harmful self-medication practices among her undergraduates.

\section{Materials and methods}

\section{Description of study area}

This study was carried out in Adeleke University which is situated in an ambient and serene environment at Ede, Osun State, Nigeria. It is a higher institution of learning with six faculties and twenty-six Departments. The Faculties include the Faculty of Business and Social Sciences (FBSS), Faculty of Arts (FOA), Faculty of Science (FOS), Faculty of Law (FOL), Faculty of Engineering (FOE) and Faculty of Basic Medical Sciences (FBMS).

\section{Study design}

It was a descriptive cross-sectional study.

\section{Study population}

This comprised of undergraduate students in Adeleke University, Ede, Osun State.

\section{Exclusion criteria}

All administrative and non-administrative staff, post graduate students and off-campus students of Adeleke University were excluded. Students who did not give voluntary consent were also excluded from participating in the study. 


\section{Calculation of sample size}

This was determined by adopting Leslie and Kish formula for single proportion. The desired minimum sample size was estimated at $380 ; 10 \%$ of the estimated sample size was added to make up for possible non-response, which brought the minimum sample size to 418 .

\section{Sampling technique}

A stratified random sampling method was used to select respondents from various levels in Faculties.

\section{Instrument of study and method of data collection}

A 30-item semi-structured self-administered questionnaire was used by 3 trained research assistants (RAs) to collect information from the respondents. It included questions on their socio-demographic characteristics, knowledge on self-medication and its harmful effects and practice of self-medication. Distribution of questionnaires was mainly carried out during the day when students could be gotten in their classrooms.

\section{Data analysis}

Data was analyzed using the Statistical Product for Service Solution (SPSS) version 21. Sociodemographic variables and respondents' responses were summarized and presented using frequency tables and charts. Bivariate analysis using Chi-square test statistics was employed to explore relationship between two categorical variables. Confidence limit was set at $95 \%$ and $p$-value of $\leq 0.05$ as the significant level.

\section{Scoring of outcome variable}

A 5-point scale measured knowledge of self-medication. Respondents with scores greater than 2 were categorized as having good knowledge. A 3-point scale measured practice of self-medication with respondents who scored greater than 1 categorized as having poor practice (meaning the respondent indulged in self-medication).

\section{Ethical considerations}

Written informed consent was obtained from the respondents before administering the questionnaires and confidentiality was ensured.

\section{Limitation of the study}

Respondents' recall bias, which we believe was limited to the barest minimum because they were assured of confidentiality and anonymity.

\section{Results}

A total of 418 questionnaires were distributed and retrieved, giving a response rate of $100 \%$. Table 1 shows the socio-demographic characteristics of respondents. Mean age of respondents was $19.89 \pm 2.83$ years. The age groups of $15-19$ years and 20-24 years had 191(45.7\%) and $195(46.7 \%)$ respondents respectively. Two hundred and nineteen (52.4\%) were male, 148 (35.7\%) and 148 (35.7\%) were students of the Faculty of Business and Social Sciences and the Faculty of Basic Medical Sciences respectively.

Table 1. Socio-demographic characteristics of the respondents

\begin{tabular}{|c|c|c|}
\hline Variables & Frequency & Percentage \\
\hline Age (in years) & & \\
\hline $15-19$ & 191 & 45.7 \\
\hline $20-24$ & 195 & 46.7 \\
\hline $25-29$ & 32 & 7.7 \\
\hline Mean age $19.89 \pm 2.83$ years & & \\
\hline $\begin{array}{l}\text { Sex } \\
\text { Female }\end{array}$ & 199 & 47.6 \\
\hline
\end{tabular}


DOI: 10.21522/TIJPH.2013.SE.19.01.Art014

ISSN: $2520-3134$

\begin{tabular}{lll}
\hline Male & 219 & 52.4 \\
\hline Faculty & & \\
Business/Social Sciences & 148 & 35.7 \\
Basic Medical Sciences & 95 & 22.7 \\
Sciences & 71 & 17.0 \\
Arts & 33 & 7.9 \\
Engineering & 14 & 3.3 \\
Law & 57 & 13.6 \\
\hline Year & & \\
100 & 122 & 29.2 \\
200 & 174 & 41.6 \\
300 & 54 & 12.9 \\
400 & 68 & 16.3 \\
\hline
\end{tabular}

Most of the respondents, 409 (97.8\%) had ever-heard about self-medication. The most common source of information were friends and family $(83.5 \%)$. Other sources cited include the internet, television, radio and newspapers.

Two hundred and seventy-six respondents $(66.0 \%)$ had good knowledge on self-medication though 71 respondents $(17.0 \%)$ did not know the correct definition of self-medication. Possible side effects of self-medication cited by respondents included treatment failure $166(39.7 \%)$, antibiotic resistance 152 (36.4\%) and drug reactions 87 (20.8\%) (Table 2).

Table 2. Knowledge on self-medication

\begin{tabular}{lll}
\hline Variables & Frequency & Percentage (\%) \\
\hline $\begin{array}{l}\text { Definition of self-medication } \\
\text { Taking drugs without medical } \\
\text { consultation* }\end{array}$ & 324 & 77.5 \\
$\begin{array}{l}\text { Consumption of drugs without a } \\
\text { doctor's prescription* }\end{array}$ & 12 & 2.9 \\
$\begin{array}{l}\text { Is a human behaviour in which a } \\
\text { substance is self-administered to }\end{array}$ & 11 & 2.6 \\
treat physical or psychological & 71 & 17.0 \\
ailments* & & \\
Don't know & & \\
\hline Knowledge on harmful effects** & & \\
Treatment failure & 166 & 39.7 \\
Antibiotic resistance & 152 & 36.4 \\
Drug reaction & 87 & 20.8 \\
May lead to death & 10 & 2.4 \\
\hline
\end{tabular}

* Correct answer

**Multiple responses

Table 3 shows that 321 (76.8\%) respondents practice self-medication. Common ailments which the respondents reportedly treated with self-medications included diarrhea (28.0\%), fever (27.8\%), cough $(27.3 \%)$ and sore throat $(20.1 \%)$.

Table 3. Practice of self-medication

\begin{tabular}{lll}
\hline Practice & Frequency & Percentage $(\%)$ \\
\hline Indulgence in self-medication & \\
Yes 32176.8 & \\
No 9723.2 & \\
& \\
\hline
\end{tabular}




\section{Health conditions treated with medication}

Fever 11627.8

Cough 11427.3

Diarrhoea 11728.0

Sore throat 8420.1

Others e.g. body aches 19646.9

\section{Source of procurement of medications}

Patent medicine store 23856.9

Leftovers from previous prescription 13231.6

Online stores/e-shopping 6114.6

At the bivariate analysis level, age $(\mathrm{p}=0.028)$ and $\mathrm{sex}(\mathrm{p}=0.001)$ were statistically significantly associated with knowledge on self-medication. Sex $(p=0.006)$ was statistically significantly associated with practice on self-medication (Table 4 and 5).

Table 4. Relationship between selected socio-demographic characteristics of respondents and knowledge on self-medication

\begin{tabular}{|l|}
\hline Variables Good knowledge Poor knowledge $\mathbf{X}^{2} \mathbf{P}$ value \\
\hline Age \\
15-19 70.729 .3 \\
$20-2465.134 .97 .1610 .028$ \\
$25-2946.953 .1$ \\
\hline Sex \\
Female 74.425 .6 \\
Male 58.9 41.1 11.159 0.001 \\
\hline Level \\
100 68.9 31.1 \\
20067.232 .81 .3610 .715 \\
30061.138 .9 \\
40063.236 .8 \\
\hline
\end{tabular}

Table 5. Relationship between socio-demographic characteristics of respondents and practice of self-medication

\begin{tabular}{|l|}
\hline Variables Good practice Poor practice $\mathbf{X}^{2} \mathbf{P}$ value \\
\hline Age \\
$15-1940.359 .7$ \\
$20-2430.869 .26 .4540 .168$ \\
$25-2946.953 .1$ \\
\hline Sex \\
Female 28.671 .4 \\
Male 43.4 56.6 10.351 0.006 \\
\hline Level \\
10041.059 .0 \\
20032.867 .25 .5400 .477 \\
30031.568 .5 \\
40041.258 .8 \\
\hline
\end{tabular}

In Figure 1, drugs that respondents reported as being frequently purchased for self-medication is diagrammatically presented as analgesics (55.5\%), antimalarial (26.1\%), antibiotics (10.8\%) and cough syrups $(9.1 \%)$.

Figure 2 shows that the low cost of self-treatment (23.0\%), convenience (48.6\%) and a lack of trust in health care provider $(24.6 \%)$ were reasons offered by the respondents for indulging in selfmedication. 


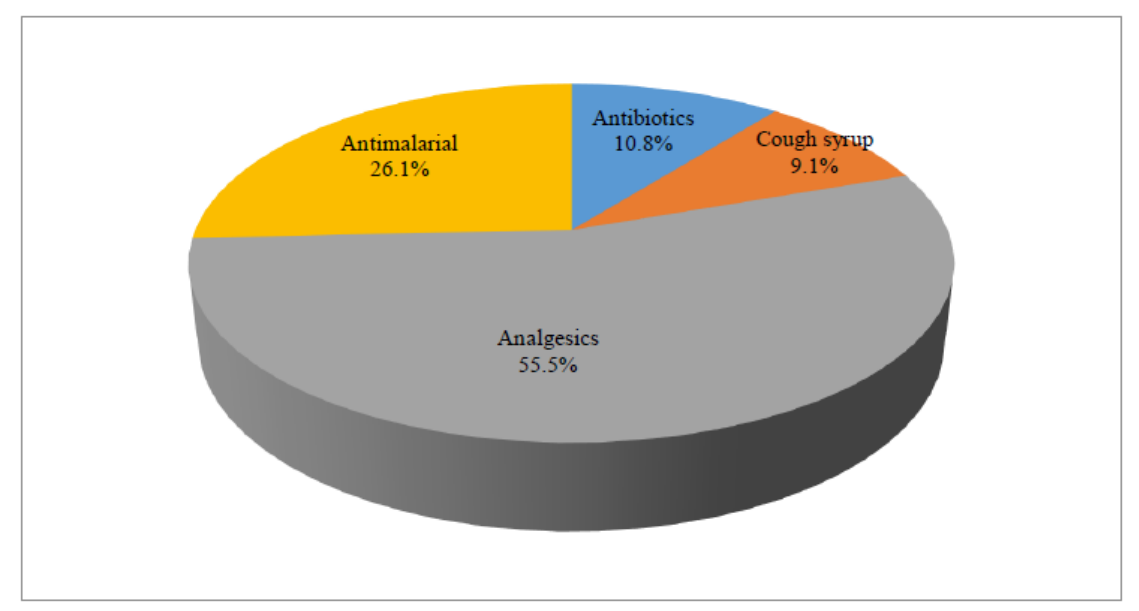

Figure 1. Drugs used for self-medication by respondents

*multiple responses apply

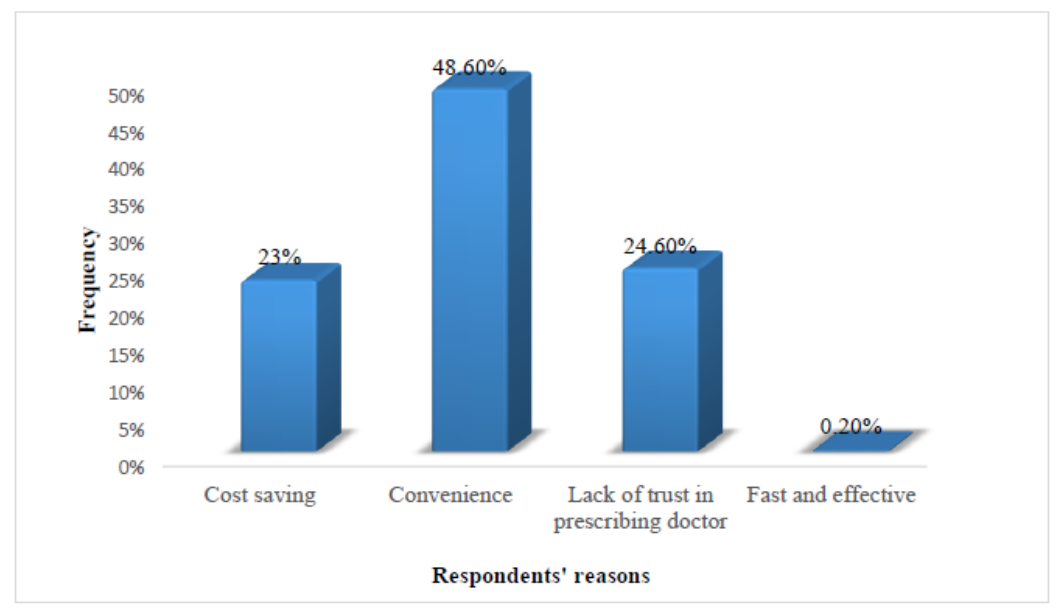

Figure 2. Reasons for practicing self-medication

*multiple responses apply

\section{Discussions}

The patterns of sociodemographic characteristics among the respondents in this study was found to be unlike that observed in a study conducted in Northern Nigeria by Musa et al. (2016) where ages of respondents were mainly within the range of 20-29 years. Majority of the respondents in this study were within the age range of 15-24 years. However, this is a normal phenomenon for many undergraduates in the Southwestern parts of Nigeria where education is more readily pursued.

There was a very high level of awareness about self-medication (97.8\%) amongst the undergraduates in this study. This is corroborated by studies by Oluwole, Joseph, Olujide, Kabir., Oladele, Paul and Olaniyan (2016) and Musa et al. (2016) where awareness among respondents was also very high $(94.8 \%)$ and $95.0 \%$ respectively. The main source of information about self-medication was cited as friends/ families (83.5\%), akin to findings by Musa et al., (2016). Though undergraduates in Adeleke University are required to attend life seminars every semester where they are availed information on various issues including health-related ones, it was not mentioned as a source of information. This calls for the attention of the University's management in modifying these seminars to include topics on selfmedication as being better informed will more readily enable students embrace positive health-seeking behaviors.

With respect to the respondents' level of knowledge, more than half $(66.0 \%)$ had good knowledge on self-medication. Majority (83\%) gave correct definitions of self-medication. This can be attributed to the fact that as students, they are believed to be exposed to a variety of communication channels and 
also retain information obtained for long periods. A study conducted in Delta state, Nigeria among secondary school students also found out that $75 \%$ had good knowledge on the harmful effects of selfmedication (Iyeke and Onoharigho, 2016).

This study found that a high proportion $(76.8 \%)$ of the respondents practiced self-medication despite having knowledge on the harmful effects of self-medication. Findings from a study conducted in Nepal among medical students revealed similar situation (Raj and Sujata, 2016). Reasons proffered for practicing self-medication included convenience (48.6\%), lack of trust in prescribing doctors $(24.6 \%)$, cost saving $(23.0 \%)$ and fast \& effective $(0.2 \%)$. In an Ethiopian study, other reasons for practicing selfmedication were cited as the respondents' prior experience $(39.10 \%)$ and mildness of the illness (37.50\%) (Girma et al., 2011). Common health problems for which self-medication was practiced included aches and pains (46.9\%), diarrhea (28.0\%), fever (27.8\%) and cough (27.3\%) as corroborated by Musa et al. (2016). Notable amongst the drugs used for self-medication were analgesics $(55.5 \%)$ and anti-malarial (26.1\%). This is similar to situation in Iran where major drugs used for self-medication were cold and cough medications (94.5\%) and analgesics (89.9\%) (Marziyeh, Maryam, Farzaneh, Fatemeh, Ensiyeh, Abbas and Payam, 2016). An explanation for this may be the presence of medicine stores and vendors densely located within Ede, where drugs can be purchased quite easily over the counter. It is also believed that students resume school with pre-purchased medications stashed in their belongings for use once the feeling of ill health is suspected.

Furthermore, the study found that there was a statistically significant relationship between age and knowledge of harmful effects of self-medication $(\mathrm{p}=0.028)$. Those within the age group of $15-19$ years had more knowledge on self-medication than those aged older. Also, there was a statistically significant relationship between sex and knowledge on self-medication $(\mathrm{p}=0.01)$ as female students were found to have more knowledge on self-medication than their male counterparts. There was a statistically significant relationship between the sex of the respondents and practices of self-medication $(\mathrm{p}=0.006)$. A higher proportion of male students had good practices in comparison with the females. Despite females having better knowledge on self-medication, this obviously did not translate into good practice. This is probably due to the potential for females to experience a greater burden of health issues for which medication might be needed on short notice such as dysmenorrhea.

\section{Conclusion}

This study concluded that there was a high level of awareness $(97.8 \%)$, knowledge $(66.0 \%)$ and indulgence in poor practice of self-medication $(76.8 \%)$ among undergraduates of Adeleke University. There was a cognitive dissonance between the respondents' knowledge and practice of self-medication as knowledge did not translate into good practice (the proportion of students who had poor practice was quite high).

\section{Recommendations}

Efforts should be intensified at the University level to develop interventions that would encourage positive behavior changes such as seeking medical consultation. Information, Education and Communication (IEC) materials should be employed in sharing information on the harmful effects of self-medication to aid better understanding of its consequences. At the community level, strict rules and penalties regarding unauthorized drug advertisement or sale should be enforced. The creation of health clubs/associations should be welcomed so as to create a more personal platform through which students can clarify issues on self-medication (and other health matters) and impact can be made.

\section{Acknowledgements}

Profound gratitude goes to Professor Esther Olufunmilayo Asekun-Olarinmoye for professional guidance.

\section{References}

[1]. Girma B.G., Diriba A.G., Zerihun A.K., Derbew F.B., Abera H.B., Mussie G.H., Gebremedhin S.H., Naod G.A., Raghavendra Y. and Abrham W.D., (2011). Self-medication practices among Health Sciences Students: The case of Mekelle University, Journal of Applied Pharmaceutical Science, 1(10), 183-189. 
[2]. Goldsworthy R. \& Mayhorn C. (2009) Prescription medication sharing among adolescents: Prevalence, Risks and Outcomes, Journal of Adolescent Health; (45)6, 634-637.

[3]. Hussain S., Malik F., Hameed A., Ahmad S., \& Riaz H. (2010). Exploring health-seeking Behaviour, medicine use and self-medication in urban and rural Pakistan. Southern Med Review; 3(2):32-34.

[4]. Iyeke P \& Onoharigho F., (2016) Knowledge of Hazards of Self-Medication among Secondary School Students in Ethiopia East Local Government Area of Delta State. Institute of Education, Delta State University, Nigeria. 7(5), 2222-1735

[5]. Kumar N., Kanchan B, Unnikrishnan, T., Rekha, \& Mithra P. (2013). Perceptions and Practices of SelfMedication among Medical Students, Coastal South India. 8(8).

[6]. Loyola F.A., Uchoa E, Firmo J.O. \& Lima-Costa M.F., (2005). A population- based study on the use of medications by elderly Brazilians. The Bambui Health and Aging Survey (BHAS). Cad Saude Publica, 21, 545553.

[7]. Marziyeh Z., Maryam D., Farzaneh B., Fatemeh E., Ensiyeh J., Abbas A. \& Payam K., (2016). Prevalence and Causes of Self Medication among Medical Students of Kerman University of Medical Sciences, Iran, 8(11), 1916-9736.

[8]. Musa Y., Awosan K., Ibrahim M., Abdullahi Z., Jafaar M., Peter G., Anthony O., \& Isah B. (2016). Knowledge and Practice of Self-Medication among Undergraduate Students of Usman-Danfodio University, Sokoto. Annals of International Medical and Dental Research; 2 (1):83-8.

[9]. Oluwole A., Joseph O., Olujide J., Kabir A., Oladele AA, Paul OA \& Olaniyan T., (2016), Self-medication among health workers in a tertiary institution in South-West Nigeria, 24.312.8146.

[10]. Omolase C., Adeleke O., \&Afolabi A.O. (2012). Self-Medication amongst General Outpatients in Community Hospital; Annals of Ibadan Postgraduate Medicine, Nigeria 5, 64-67

[11]. Osemene K. \& Lamikanra A. (2012). Study of the prevalence of self-medication among university students Southwestern Nigeria.; 11(4):683-689.

[12]. Raj Kumar M \& Sujata Sharma, (2016) Knowledge, Attitude and Practice of Self-Medication among Medical Students Chitwan Medical College, Tribhuwan University, Nepal, 4(1), 89-96: 2320-1959.

[13]. Sarahroodi S., Arzi A., Sawalha A.F. \& Ashtarinezland A. (2010). Antibiotics Self-medication among Southern Iranian University Students. International Journal of Pharmacology. 6(1), 48-52.

[14]. William Osler, Phalke V., Phalke D, \& Durgawale P. (2006). Self-medication practices in rural Maharashtra. Indian Journal of Community Medicine. (31) 34-5.

[15]. World Health Organization (2012). Department of Essential Drugs and Other Medicines, World Health Organization, Report of the 4th WHO Consultative Group on the Role of the Pharmacist WHO/DAP/98.13. Accessed on 26/9/2017

[16].World Self-Medication Industry (2010). Benefits of Responsible Self-Medication Accessed on 26/9/2017 http://www.wsmi.org/publications.html 